\title{
High-dose steroids prevent placental dysfunction after fetal cardiac bypass
}

\begin{abstract}
Surgical treatment of certain congenital heart lesions in utero may have a therapeutic advantage over postnatal repair or palliation. For fetal heart surgery to be possible, a method to support the fetal circulation is necessary. Early experimental attempts at fetal cardiac bypass were unsuccessful because of increased placental vascular resistance during and after fetal cardiac bypass, which led to decreased placental flow, fetal asphyxia, and death. Our laboratory has demonstrated that the administration of indomethacin (a cyclooxygenase inhibitor) during fetal cardiac bypass prevents this increase in placental vascular resistance during and after fetal cardiac bypass. The specific mechanism by which indomethacin achieves this effect is likely to be either by inhibiting the production of a placental vasoconstrictive prostaglandin or by diverting substrate from the cyclooxygenase pathway to the lipoxygenase pathway, thereby potentially increasing the production of a placental vasodilating leukotriene. To examine these potential mechanisms in more detail, we inhibited both prostaglandin and leukotriene synthesis at the phospholipase stage with high-dose steroids. Fourteen fetal lambs were used in the study. Six animals received indomethacin $(3 \mathrm{mg} / \mathrm{kg}$ ), four received high-dose steroids (Solu-Medrol $50 \mathrm{mg} / \mathrm{kg}$ ), and four animals were used as controls. Observations were made during a 1-hour prebypass period, a 30-minute bypass period, and a 2-hour postbypass period. Placental blood flow and placental vascular resistance were calculated at four times during the experiments: before sternotomy; after sternotomy; during bypass at $\mathbf{3 0}$ minutes; and $\mathbf{3 0}$ minutes after cessation of bypass. Similar to indomethacin, high-dose steroid administration during fetal cardiac bypass prevents the rise in placental vascular resistance and preserves placental blood flow during and after fetal cardiac bypass. This study suggests that the production of a placental vasoconstrictive prostaglandin is responsible for the increase in placental vascular resistance and decrease in placental blood flow observed after fetal cardiac bypass. (J THORAC CARDIOvaSC SURG 1994;107:116-25)
\end{abstract}

Joseph F. Sabik, MD (by invitation), Markus K. Heinemann, MD (by invitation), Renato S. Assad, MD (by invitation), and Frank L. Hanley, MD (by invitation), Boston, Mass. Sponsored by Aldo R. Castaneda, MD, Boston, Mass.

$\mathrm{T}_{\text {he }}$ he correction of certain congenital heart defects in utero may be more beneficial than postnatal therapy. We have been interested in developing an extracorporeal cardiac bypass method that may be used during in utero fetal cardiac surgery. Early attempts at cardiac bypass in the

From the Department of Cardiovascular Surgery, Children's Hospital of Boston, Harvard Medical School, Boston, Mass.

Read at the Seventy-second Annual Meeting of The American Association for Thoracic Surgery, Los Angeles, Calif., April 26-29, 1992.

Address for reprints: Frank L. Hanley, MD, Department of Cardiothoracic Surgery, University of California at San Francisco, 505 Parnassus Ave., San Francisco, CA 94143.

Copyright ${ }^{\circledR} 1994$ by Mosby-Year Book, Inc.

$0022-5223 / 94 \$ 1.00+.10 \quad \mathbf{1 2} / \mathbf{6} / \mathbf{5 0 4 5 6}$ fetal lamb were unsuccessful because placental vascular resistance increased and placental blood flow decreased during and after fetal extracorporeal support. ${ }^{1-3}$ This led to fetal asphyxia and death soon after the fetuses were weaned from cardiac bypass. ${ }^{1-3}$ We have shown that, with the administration of indomethacin, this rise in placental vascular resistance and decrease in placental blood flow is avoided, and placental blood flow and placental respiratory gas exchange is maintained during and after fetal extracorporeal support. ${ }^{4}$

Indomethacin inhibits the enzyme cyclooxygenase, which converts arachidonic acid into a peroxy-acid, the precursor of all prostaglandins. Many prostaglandins are known potent placental vasoconstrictors. By inhibiting this cyclooxygenase, indomethacin not only inhibits all 
prostaglandin synthesis, but may also increase leukotriene production by diverting arachidonic acid from the cyclooxygenase pathway to the lipoxygenase pathway, thereby increasing synthesis of leukotrienes. We therefore theorized that indomethacin may prevent the increase in placental vascular resistance during fetal cardiac bypass either by preventing the synthesis of a placental vasoconstricting prostaglandin or by increasing the synthesis of a placental vasodilating leukotriene.

To test this theory and evaluate which of these potential mechanisms is more likely to be responsible for preventing the increase in placental vascular resistance observed during fetal cardiac bypass, we inhibited both leukotriene and prostaglandin production at the phospholipase stage with high-dose methylprednisolone sodium succinate (Solu-Medrol). A positive response with methylprednisolone would support the theory that indomethacin exerts its action through the arachidonic acid pathway and would also clarify the details of the mechanism.

The fetal lambs were divided into three groups and placed on fetal cardiac bypass. Experiments were performed with a standardized fetal lamb cardiac bypass preparation. Six fetal lambs received indomethacin and four received methylprednisolone before fetal cardiac bypass. Four fetal lambs were used as controls and did not receive any drug. Fetal hemodynamics, arterial blood gases, placental blood flow, cardiac output, and placental vascular resistance were determined and compared among the three groups.

\section{Methods}

Anesthetic management. Fourteen pregnant ewes of 110 to 120 days gestation were fasted for 24 to 48 hours. Anesthesia was induced with ketamine 30 to $40 \mathrm{mg} / \mathrm{kg}$ intramuscularly. The ewes were intubated endotracheally and their lungs were ventilated with $100 \%$ oxygen to keep their arterial oxygen saturation at $99 \%$ and their arterial carbon dioxide tension $\left(\mathrm{PCO}_{2}\right)$ in the physiologic range during pregnancy of 25 to 35 torr. ${ }^{5}$ Anesthesia was maintained with intravenous ketamine at 300 to $500 \mathrm{mg} / \mathrm{hr}$. A Foley catheter was placed and urine output was monitored. A femoral arterial line was placed, and maternal heart rate and blood pressure were monitored.

Procedure. The uterus was exposed through a midline laparotomy. A uterine vein was identified and cannulated. Oxygen tension $\left(\mathrm{PO}_{2}\right)$ of the uterine vein was checked every 15 to 30 minutes to monitor uterine perfusion, and aggressive fluid replacement was performed to prevent maternal dehydration and subsequent hypoperfusion of the uterus. Intravenous fluid was administered liberally to keep the ewe's hematocrit value below 25\% and uterine vein $\mathrm{PO}_{2}$ above $45 \mathrm{~mm} \mathrm{Hg}$.

A 2 to $3 \mathrm{~cm}$ hysterotomy was made over a fetal hind limb, and the fetal hind limb was removed from the uterus. An intramuscular injection of ketamine, $50 \mathrm{mg} / \mathrm{kg}$, was given to the fetal lamb. A hind limb artery and vein were cannulated. The venous catheter was used to inject radioactive microspheres, and the arterial line was used to monitor fetal heart rate, blood pressure, hematocrit value, and arterial blood gases and to be used as a withdrawal catheter during microsphere injections. The hind limb was returned to the uterus, and the hysterotomy was closed.

An 8 to $10 \mathrm{~cm}$ second hysterotomy was performed to expose the fetal sternum, neck, and fore limb. A fore limb vein and artery were cannulated. The arterial line was used as a withdrawal catheter during microsphere injections, and the venous line was used to administer nitroprusside (Nipride) during cardiac bypass.

A fetal neck incision exposed a carotid artery, and the carotid artery was cannulated toward the heart with a No. 8, 10 , or 12 arterial perfusion cannula. A midline sternotomy was performed, the pericardium was opened, and pericardial retention sutures were placed. A pulmonary arterial line was placed in the right ventricular outflow tract and advanced through the pulmonary valve into the main pulmonary artery. This line was used to monitor pulmonary artery pressures and as a withdrawal catheter during microsphere injections. The right atrial appendage was cannulated with a No. 14 or 16 venous cannula, and the fetus was supported by normothermic nonpulsatile cardiac bypass for 30 minutes. In four experiments, methylprednisolone $(50 \mathrm{mg} / \mathrm{kg})$ was given to both the ewe and fetus before bypass. In six experiments indomethacin was administered to the fetal lambs as previously described, ${ }^{4}$ and in four experiments no drug was given.

One to 2 hours after cessation of fetal cardiac bypass, the ewe and fetus were killed and the fetus and placenta were removed from the uterus. The locations of all the fetal withdrawal catheters were confirmed and the fetal organs were dissected and removed.

All animals received humane care in compliance with the "Principles of Laboratory Animal Care" formulated by the National Society for Medical Research and the "Guide for the Care and Use of Laboratory Animals prepared by the National Academy of Sciences and published by the National Institutes of Health. The experimental protocol was reviewed and approved by the Children's Hospital of Boston Committee on the Care and Use of Laboratory Animals.

Fetal cardiac bypass. A Bio-Medicus centrifugal conical pump (Medtronic Bio-Medicus, Eden Prairie, Minn.), primed with either maternal or donor sheep blood, was used as the pumping device during cardiac bypass. Because the circuit contained no oxygenator, the placenta was the sole gas exchanger during bypass. Flows were adjusted to approximate a normal fetal cardiac output of approximately $400 \mathrm{ml} / \mathrm{min}$ per kilogram of fetal weight. After a 30-minute cardiac bypass period, the fetus was weaned from cardiac bypass, and the venous cannula was removed. During bypass, nitroprusside was administered (10 to $20 \mu \mathrm{g} / \mathrm{kg}$ per minute) to keep fetal blood pressure in the same range as prebypass levels. Nitroprusside was usually needed in the group administered indomethacin, never needed in the fetuses that received methylprednisolone, and always needed in the control experiments.

Data accumulation. Maternal and fetal heart rate and blood pressure were continuously monitored with Statham transducers (Viggo Spectramed Inc., Critical Care Div., Oxnard, Calif.) and either a Hewlett-Packard 7758B system (Hewlett-Packard Co., Palo Alto, Calif.) or Honeywell AR-6 Simultrace recorder (Honeywell, Inc., Minneapolis, Minn.). Both maternal and fetal $\mathrm{PO}_{2}, \mathrm{PCO}_{2}, \mathrm{pH}$, bicarbonate radical $\left(\mathrm{HCO}_{3}\right)$, and hematocrit 


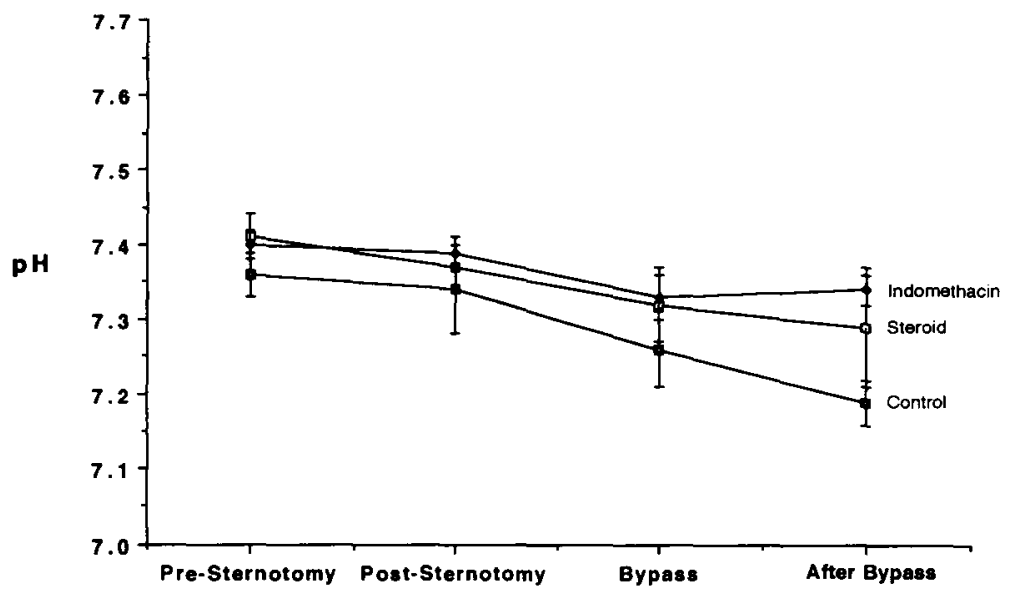

Fig. 1. Fetal arterial pH for the control and indomethacin- and methylprednisolone-treated groups. All three groups become progressively acidotic. Data are presented as mean \pm standard error of the mean.

Table I. Arterial blood gas data

\begin{tabular}{|c|c|c|c|c|}
\hline & $\begin{array}{c}\text { Before } \\
\text { sternotomy }\end{array}$ & $\begin{array}{c}\text { After } \\
\text { sternotomy }\end{array}$ & Bypass & $\begin{array}{c}\text { After } \\
\text { bypass }\end{array}$ \\
\hline \multicolumn{5}{|l|}{$\mathrm{pH}$} \\
\hline a & $7.41 \pm 0.03$ & $7.37 \pm 0.03$ & $7.31 \pm 0.05$ & $7.29 \pm 0.08$ \\
\hline$b$ & $7.40 \pm 0.02$ & $7.38 \pm 0.02$ & $7.33 \pm 0.03$ & $7.34 \pm 0.03$ \\
\hline $\mathrm{c}$ & $7.36 \pm 0.02$ & $7.33 \pm 0.06$ & $7.26 \pm 0.05$ & $7.19 \pm 0.03$ \\
\hline \multicolumn{5}{|l|}{$\mathrm{PO}_{2}$} \\
\hline $\mathrm{a}$ & $23.93 \pm 3.42$ & $19.33 \pm 1.52$ & $28.98 \pm 6.77$ & $30.60 \pm 7.39$ \\
\hline $\mathrm{b}$ & $20.92 \pm 2.64$ & $20.22 \pm 2.28$ & $31.07 \pm 4.50$ & $26.38 \pm 4.50$ \\
\hline c & $21.30 \pm 3.85$ & $18.10 \pm 2.92$ & $23.60 \pm 2.44$ & $14.43 \pm 1.25$ \\
\hline \multicolumn{5}{|c|}{$\mathrm{PCO}_{2}$ gradient } \\
\hline $\mathrm{a}$ & $11.90 \pm 2.50$ & $15.20 \pm 1.08$ & $14.43 \pm 1.47$ & $15.87 \pm 1.01$ \\
\hline $\mathrm{b}$ & $10.37 \pm 0.83$ & $12.30 \pm 1.85$ & $13.62 \pm 0.75$ & $11.35 \pm 1.55$ \\
\hline $\mathrm{c}$ & $9.45 \pm 2.00$ & $14.63 \pm 1.90$ & $22.65 \pm 6.76$ & $26.10 \pm 4.54$ \\
\hline \multicolumn{5}{|c|}{$\mathrm{HCO}_{3}$} \\
\hline $\mathrm{a}$ & $24.13 \pm 0.75$ & $22.50 \pm 0.58$ & $20.33 \pm 1.43$ & $20.15 \pm 1.19$ \\
\hline $\mathrm{b}$ & $22.77 \pm 0.35$ & $22.28 \pm 0.71$ & $20.92 \pm 0.58$ & $19.77 \pm 0.62$ \\
\hline $\mathrm{c}$ & $21.60 \pm 2.30$ & $22.30 \pm 1.02$ & $20.27 \pm 0.79$ & $20.55 \pm 1.08$ \\
\hline
\end{tabular}

Data are given for methylprednisolone-treated $(a)$, indomethacin-treated $(b)$, and control $(c)$ groups for four times during the experiments: before sternotomy, after sternotomy, during bypass, and after bypass. Data are presented as mean \pm standard error of the mean.

value and maternal uterine vein $\mathrm{Po}_{2}$ were checked every 15 to 30 minutes on a Ciba-Corning 280 blood gas system (CibaCorning Diagnostics Corp., Medfield, Mass.) before, during, and for 1 to 2 hours after fetal cardiac bypass.

Radioactive microspheres were used to determine fetal cardiac output, placental blood flow, and individual organ blood flows at four times during each procedure: before sternotomy, after sternotomy, during cardiac bypass, and 30 minutes after cessation of cardiac bypass. During the bypass microsphere injection, the heart was electrically fibrillated for a brief period. Microspheres were injected to ensure at least 400 microspheres per organ counted. ${ }^{6}$ The triple withdrawal catheter method was used to determine cardiac output and individual organ blood flows, and blood was withdrawn at a rate of $4 \mathrm{ml} / \mathrm{min}$ per catheter. 6,7

The fetal organs and placenta were dissolved overnight in a solution of $2 \mathrm{~N}$ potassium hydroxide in $100 \%$ methanol at $60^{\circ}$
C. Individual organ and placental radioactivity was counted in an LKB Wallac 1282 gamma counter (Wallac, Inc., Gaithersburg, Md.) with the aid of a Dell System 200 computer (Dell Computer Corp., Austin, Tex.). Cardiac output and placental blood flow were calculated as previously described. ${ }^{7}$ Placental vascular resistance was calculated by dividing mean arterial blood pressure by placental blood flow.

Statistical methods. Statistical analyses were performed with a statistical program (Statworks, Cricket Software; Computer Associates, Mt. Laurel, N.J.). Student's unpaired $t$ test was used, and statistical significance was declared at $p$ values less than 0.05 .

\section{Results}

Hemodynamics. Maternal and fetal heart rate and blood pressure were in the normal range in all three 


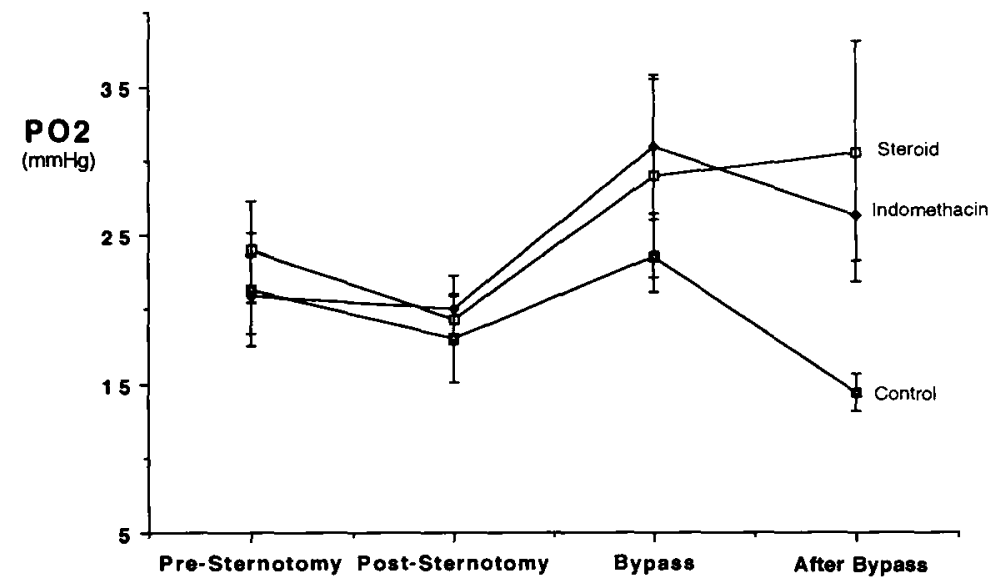

Fig. 2. Fetal arterial $\mathrm{PO}_{2}$ for the control and indomethacin- and methylprednisolone-treated groups. Arterial $\mathrm{PO}_{2}$ rises in all three groups during bypass, but it tended to decrease in the control group after bypass. The difference in arterial $\mathrm{PO}_{2}$ after bypass between the control and methylprednisolone-treated groups approached significance $(p=0.07)$. Data are presented as mean \pm standard error of the mean.

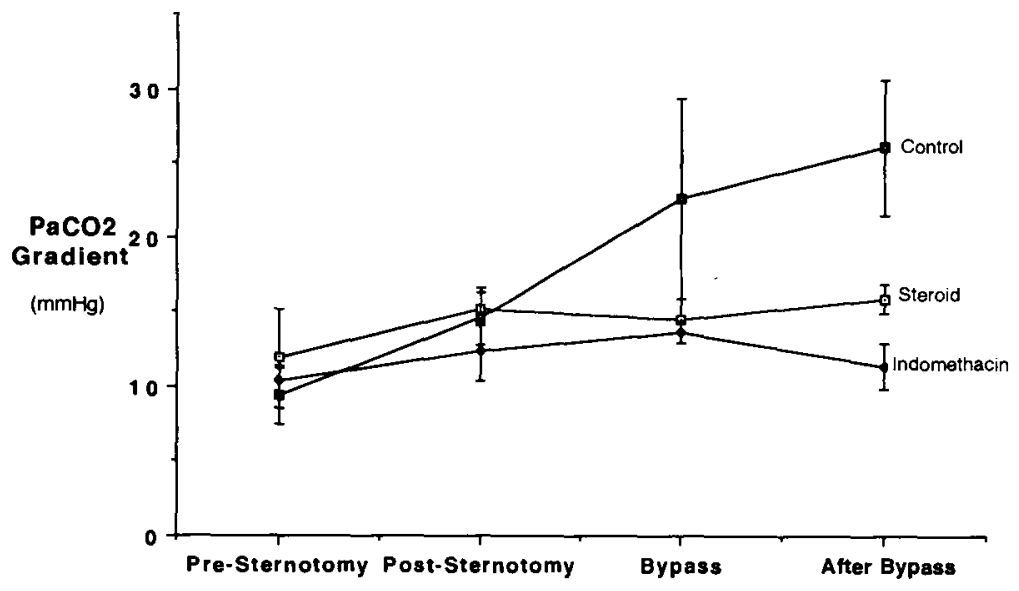

Fig. 3. The arterial $\mathrm{PCO}_{2}\left(\mathrm{PaCO}_{2}\right)$ gradient between the fetal femoral arterial $\mathrm{PCO}_{2}$ and the ewe femoral arterial $\mathrm{PCO}_{2}$ for the control and indomethacin- and methylprednisolone-treated groups. The arterial $\mathrm{PCO}_{2}$ gradient had a tendency to be higher in the control group after bypass than in the methylprednisolone-treated group. This difference approached significance $(p=0.07)$. Data are presented as mean \pm standard error of the mean.

groups. ${ }^{5,14}$ Maternal heart rates were between 70 and 90 beats $/ \mathrm{min}$ and mean blood pressures were between 80 and $100 \mathrm{~mm} \mathrm{Hg}$ throughout the procedures. Fetal heart rates were between 144 and 180 beats/min and mean blood pressures were between 40 and $55 \mathrm{~mm} \mathrm{Hg}$ during the experiments. In the control group and usually in the indomethacin-treated group, fetal blood pressure would increase during cardiac bypass, and nitroprusside was administered intravenously to decrease mean fetal blood pressure to prebypass levels. In the methylprednisolonetreated fetuses nitroprusside was not necessary, because the arterial blood pressure did not rise when cardiac bypass was begun.
Arterial blood gases. The fetal prebypass values for $\mathrm{pH}$, arterial $\mathrm{PCO}_{2}, \mathrm{PO}_{2}$, and $\mathrm{HCO}_{3}$ were the same in all three groups (Table I and Figs. 1 to 4 ). These values are in the normal range for fetal lambs. ${ }^{5,8-14}$

During cardiac bypass there was an increase in femoral arterial $\mathrm{Po}_{2}$ in all groups (Fig. 2). After bypass the arterial $\mathrm{PO}_{2}$ remained elevated in the steroid- and indomethacin-treated fetuses; however, in the control group the arterial $\mathrm{PO}_{2}$ decreased after the fetuses were weaned from bypass. There was a tendency for the arterial $\mathrm{Po}_{2}$ in the fetuses treated with methylprednisolone to be higher than in the control group after bypass; however, this difference was not significant $(p=0.07)$. 


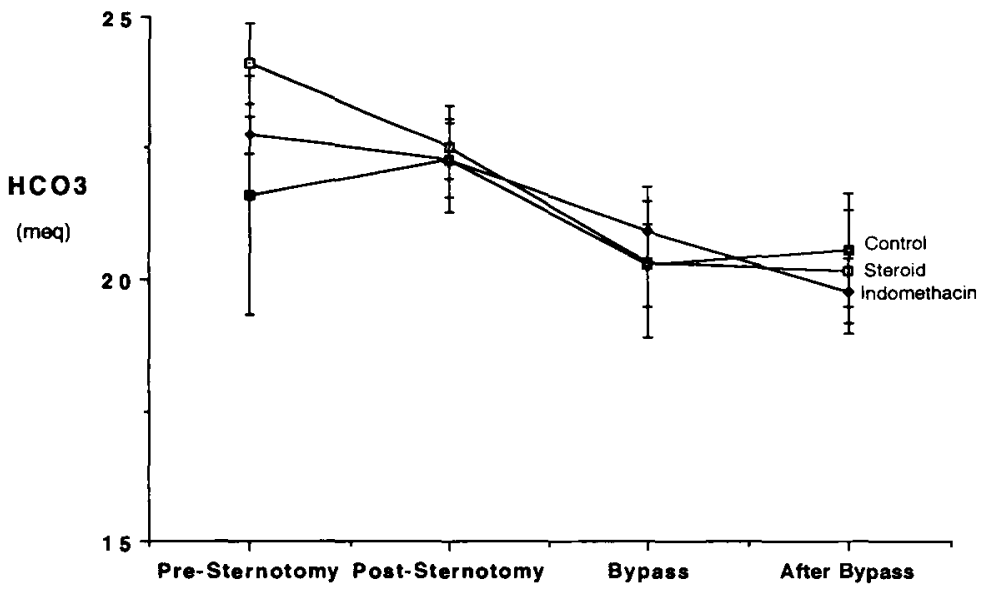

Fig. 4. The fetal arterial $\mathrm{HCO}_{3}$ for the control and indomethacin- and methylprednisolone-treated groups. There is no difference among the three groups throughout the experiment. Data are presented as mean \pm standard error of the mean.

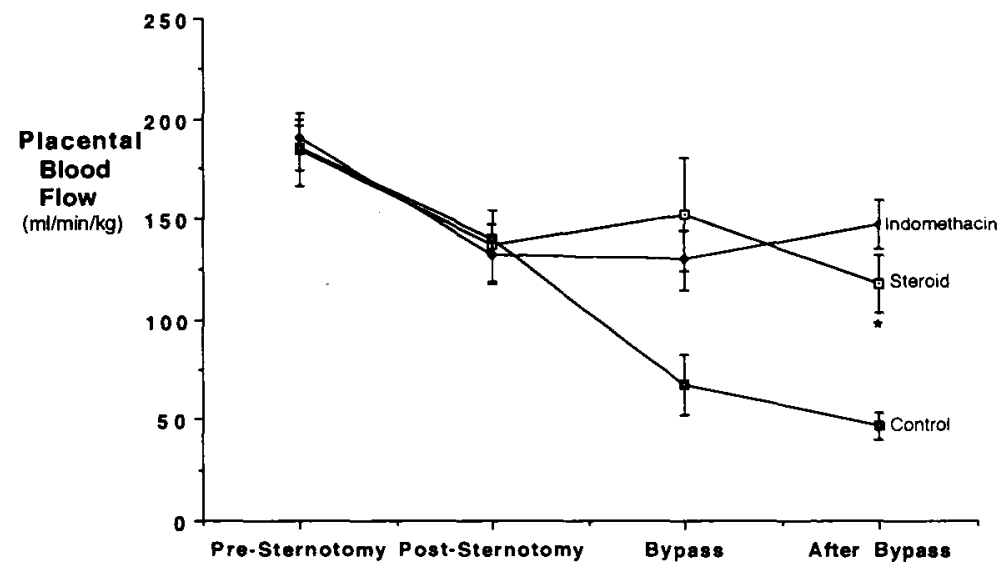

Fig. 5. Placental blood flow for the control and indomethacin- and methylprednisolone-treated groups. There is a significant difference in placental blood flow between the control and methylprednisolone-treated groups both during and after cardiac bypass. Data are presented as mean \pm standard error of the mean. ${ }^{*} p<0.04$ versus the control group.

The arterial $\mathrm{PCO}_{2}$ gradient is the difference between maternal arterial $\mathrm{PCO}_{2}$ and fetal arterial $\mathrm{PCO}_{2}$. It is a more precise way to compare placental respiratory gas exchange among the three groups than fetal arterial $\mathrm{PCO}_{2}$ because it eliminates differences in fetal arterial $\mathrm{PCO}_{2}$ caused by different levels of ventilation in the ewes. During and after fetal cardiac bypass, the arterial $\mathrm{PCO}_{2}$ gradient rose in the control group (Fig. 3). During bypass the arterial $\mathrm{PCO}_{2}$ gradient remained at prebypass levels in both the indomethacin and steroid groups. After bypass, the arterial $\mathrm{PCO}_{2}$ gradient had a tendency to be lower in both the steroid and indomethacin groups than in the control group. This difference approached significance $(p=0.07)$.
There is no difference in fetal arterial $\mathrm{HCO}_{3}$ among the three groups throughout the experiment although all three groups became progressively more acidotic during the experiments (Figs. 1 and 4 ).

Cardiac output, placental blood flow, and resistance. Similarly, the prebypass values for placental blood flow, placental vascular resistance, cardiac output, and percentage of cardiac output as placental blood flow were the same in all three groups (Table II and Figs. 5 to 8). These values are in the normal range for fetal lambs. ${ }^{5,14}$ There was a $30 \%$ decrease in placental blood flow and cardiac output after fetal sternotomy before fetal cardiac bypass. This $30 \%$ decrease in cardiac output and placental blood flow has been previously reported. ${ }^{4}$ 


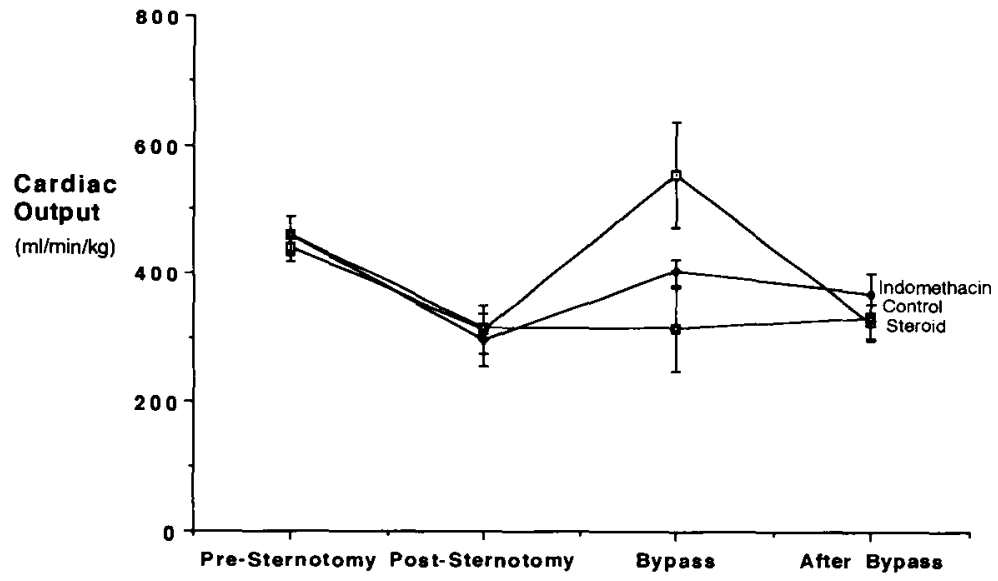

Fig. 6. Fetal cardiac output for the control and indomethacin- and methylprednisolone-treated groups. Data are presented as mean \pm standard error of the mean.

Table II. Blood flow data

\begin{tabular}{ccccc}
\hline & $\begin{array}{c}\text { Before } \\
\text { sternotomy }\end{array}$ & $\begin{array}{c}\text { After } \\
\text { sternotomy }\end{array}$ & Bypass & $\begin{array}{c}\text { After } \\
\text { bypass }\end{array}$ \\
\hline PBF & & & & $118.0 \pm 13.8$ \\
a & $184.3 \pm 18.3$ & $136.9 \pm 17.5$ & $152.2 \pm 28.0$ & $147.1 \pm 11.8$ \\
b & $191.0 \pm 9.0$ & $132.5 \pm 14.9$ & $129.6 \pm 14.4$ & $47.1 \pm 6.4$ \\
c & $185.3 \pm 11.0$ & $139.8 \pm 7.5$ & $67.4 \pm 15.3$ & $325.9 \pm 25.7$ \\
CO & & & & $369.8 \pm 29.6$ \\
a & $442.0 \pm 23.7$ & $311.8 \pm 38.8$ & $555.2 \pm 81.2$ & $331.1 \pm 36.2$ \\
b & $458.8 \pm 30.2$ & $296.1 \pm 40.6$ & $401.8 \pm 20.2$ & \\
c & $460.8 \pm 28.1$ & $315.0 \pm 4.2$ & $313.4 \pm 63.5$ & $0.59 \pm 0.10$ \\
PVR & & & & $0.59 \pm 0.10$ \\
a & $0.37 \pm 0.03$ & $0.47 \pm 0.02$ & $0.62 \pm 0.11$ & $1.38 \pm 0.24$ \\
b & $0.42 \pm 0.08$ & $0.60 \pm 0.13$ & $1.40 \pm 0.08$ & \\
C & $0.40 \pm 0.08$ & $0.49 \pm 0.09$ & & $37.5 \pm 1.6$ \\
PBF/CO & & & $27.4 \pm 2.7$ & $40.0 \pm 1.2$ \\
a & $41.5 \pm 2.1$ & $44.2 \pm 3.9$ & $32.3 \pm 3.4$ & $15.3 \pm 1.8$ \\
\hline
\end{tabular}

Data are given for methylprednisolone-treated $(a)$, indomethacin-treated $(b)$, and control (c) groups for four times during the experiments: before sternotomy; after sternotomy; during bypass; and after bypass. Data are presented as mean \pm standard error of the mean. $P B F$, Placental blood flow; $C O$, cardiac output; $P V R$, placental vascular resistance; $P B F / C O$, Percentage of cardiac output as placental blood flow.

In the control group there is a decrease in placental blood flow and an increase in placental vascular resistance during and after fetal cardiac bypass when compared with prebypass, poststernotomy levels (Table II, Figs. 5 and 7). In the indomethacin- and steroid-treated groups there are no significant changes in placental blood flow and placental vascular resistance during and after fetal cardiac bypass when compared with poststernotomy, prebypass values. After cardiac bypass, placental blood flow and placental vascular resistance are significantly different between the methylprednisolone-treated and control fetuses (Figs. 5 and 7).

The prebypass and postbypass cardiac outputs are not significantly different among the three groups (Fig. 6). During bypass, higher flow rates were obtained in the steroid- and indomethacin-treated groups than in the control group. During bypass, increased blood pressure limited flow rates in the control group. Nitroprusside was administered to decrease arterial pressure in the control group during cardiac bypass; however, it was not effective enough for bypass flow rates to be increased in the control group to match bypass flow rates obtained in the steroid- and indomethacin-treated groups. Nitroprusside was usually needed in the indomethacin-treated group to lower blood pressure, although at lower levels than in the control group. Nitroprusside was not needed in the meth- 


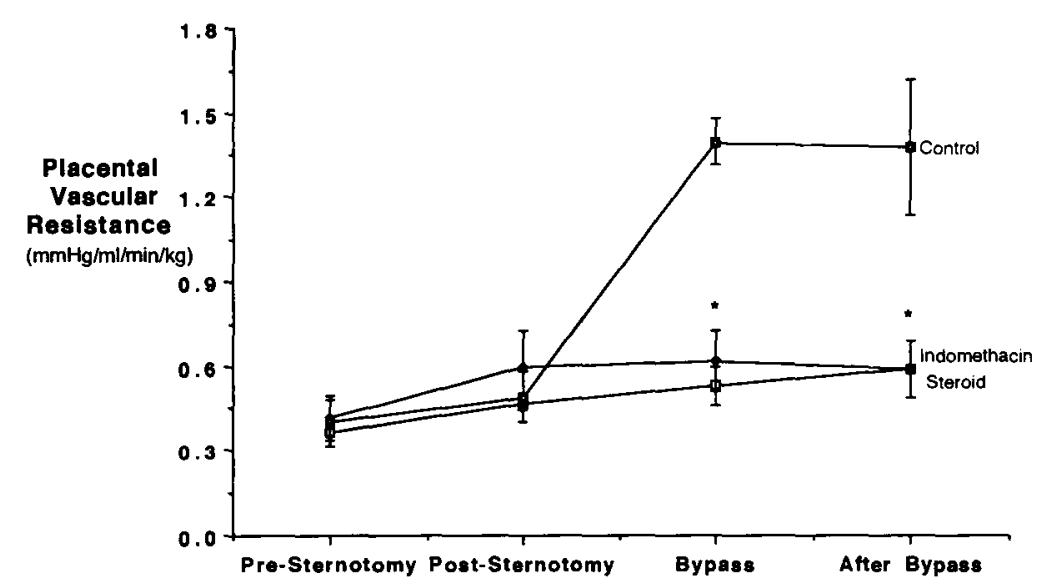

Fig. 7. Placental vascular resistance for the control and indomethacin- and methylprednisolone-treated groups. There is a significant increase in placental vascular resistance in the control group during and after bypass, whereas it remains unchanged in the indomethacin- and methylprednisolone-treated groups. Data are presented as mean \pm standard error of the mean. ${ }^{*} p<0.02$ versus the control group.

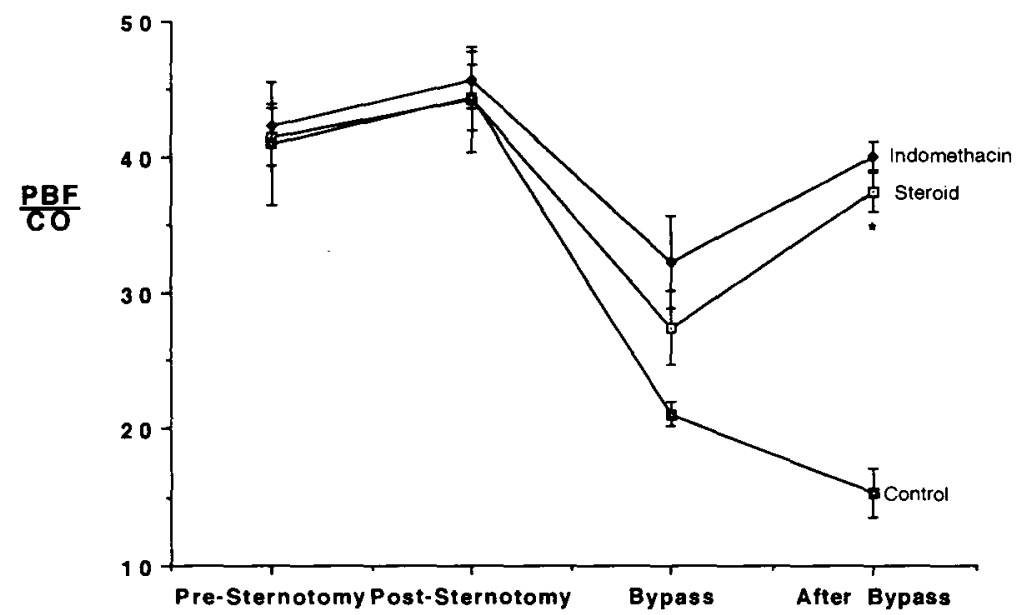

Fig. 8. Percentage of cardiac output as placental blood flow $(P B F / C O)$ for all three groups. This parameter continues to decrease in the control group after bypass, whereas in the methylprednisolone- and indomethacin-treated groups it returns to baseline. Data are presented as mean \pm standard error of the mean. ${ }^{*} p<0.001$ versus the control group.

ylprednisolone-treated group for blood pressure control. Despite this discrepancy among the groups during cardiac bypass, after weaning from cardiac bypass there was no difference in cardiac output among the three groups (Fig. 6).

Placental blood flow as a percentage of cardiac output was the same and in the normal range for all groups before bypass (Fig. 8). During bypass, this parameter decreased in all groups. After bypass in the indomethacin- and methylprednisolone-treated groups the percentage of cardiac output as placental flow returned to normal pre- bypass levels, whereas it remained significantly depressed in the control group.

\section{Discussion}

Intrauterine surgical therapy for certain forms of complex congenital heart lesions may have advantages over present day postnatal repair or palliation. The types of lesions that may benefit from this approach are those complex lesions that develop over time throughout fetal life as a result of abnormal fetal intracardiac pressures or flow patterns. ${ }^{15}$ These lesions have their origins early in 
fetal life as relatively simple primary obstructive defects; however, the abnormal flow patterns set up by these simple obstructive lesions result in progressive abnormal development of major cardiac structures, such as the heart chambers and great vessels. ${ }^{15}$ Surgically correcting the simple primary obstructive lesions in the fetal heart in utero will serve two purposes. First, it will normalize flow patterns in the abnormally developing fetal heart; second, it will provide a period of time in utero (i.e., the remainder of gestation) during which the fetal heart may recover and resume normal development. ${ }^{15}$ For fetal heart surgery to be possible, a method of performing fetal cardiac bypass will be necessary. Previous experiments with standard cardiac bypass methods have demonstrated placental dysfunction after fetal cardiac bypass. ${ }^{1-3}$ The inciting factor causing increased placental vascular resistance and placental dysfunction has remained unknown. $\mathrm{We}^{4}$ have previously shown that the administration of indomethacin, a prostaglandin synthesis inhibitor, during fetal cardiac bypass prevents the placental dysfunction normally observed after fetal cardiac bypass.

Indomethacin prevents the synthesis of all prostaglandins by inhibiting the formation of a peroxy-acid from arachidonic acid. In addition to blocking prostaglandin synthesis, indomethacin treatment might lead to an increase in leukotriene synthesis by providing more arachidonic acid that may be available to the lipoxygenase pathway. We therefore postulated that indomethacin was preventing the normally observed placental dysfunction during fetal cardiac bypass either by inhibiting the formation of a placental vasoconstrictive prostaglandin or by increasing the synthesis of a placental vasodilating leukotriene. To determine which of these mechanisms was correct and to test the general theory that indomethacin exerts its effect through the arachidonic cascade, we inhibited the release of arachidonic acid from membrane phospholipids with high-dose methylprednisolone. Arachidonic acid is the precursor of both prostaglandins and leukotrienes, and administering methylprednisolone during fetal cardiac bypass would inhibit both pathways. If the mechanism of action of indomethacin is the inhibition of the synthesis of a vasoconstrictive prostaglandin during fetal cardiac bypass, administration of methylprednisolone would exert a similar effect. If the mechanism of action of indomethacin is increased substrate presentation to the leukotriene pathway, administration of methylprednisolone would not prevent the normally observed placental dysfunction during and after fetal cardiac bypass.

Our experiments demonstrate that the use of methylprednisolone during fetal cardiac bypass prevents the increase in placental vascular resistance and preserves placental blood flow and placental respiratory gas exchange after fetal cardiac bypass. These findings suggest that both methylprednisolone and indomethacin prevent placental dysfunction during and after fetal cardiac bypass by inhibiting the production of a vasoconstrictive prostaglandin.

The prostaglandins thromboxane and prostaglandin $E_{2}$ are both known to be potent placental vasoconstrictors. ${ }^{16-}$ 25 Fetal prostaglandin $E_{2}$ serum levels have been shown to be elevated during and for several days after fetal intervention. ${ }^{18,25}$ Prostaglandin $\mathrm{E}_{2}$ serum levels have also been observed to rise in the fetal lamb just before birth. $^{18,25}$ From these observations, prostaglandin $E_{2}$ synthesis seems to occur at times of fetal stress. Fetal cardiac bypass may be a significant enough stress to the fetus to cause an increase in prostaglandin $E_{2}$ levels and placental vasoconstriction.

Thromboxane production has been observed to increase in both pediatric and adult patients supported by cardiac bypass. ${ }^{26-30}$ Fetal cardiac bypass may result in increased production of thromboxane in the fetus, resulting in placental vasoconstriction.

\section{Conclusion}

Vasoconstrictive prostaglandins are responsible for the increased placental vascular resistance and decreased placenta blood flow observed during and after fetal cardiac bypass. Further studies designed specifically to examine the roles of prostaglandin E2 and thromboxane are being planned.

\section{REFEREN CES}

1. Hawkins JA, Paape KL, Adkins TP, Shaddy RE, Gay WA. Cardiopulmonary bypass in the fetal lamb: effects of hypothermia and perfusion rate. Circulation 1988;78(Suppl):II357.

2. Richter RC, Slate RK, Rudolph AM, Turley K. Fetal blood flow during hypothermic cardiopulmonary by-pass in utero. J Cardiovasc Surg 1985;26:86.

3. Bradley SM, Hanley FL, Jennings RW, Duncan BW, Jester JA, Verrier ED. Regional blood flows during cardiopulmonary bypass in fetal lambs: the effect of nitroprusside. Circulation 1990;82(Suppl):III413.

4. Sabik JF, Assad RS, Hanley FL. Prostaglandin synthesis inhibition prevents placental dysfunction after fetal cardiac bypass. J THORAC CARDIOVASC SuRg 1992;103:733-42.

5. Assali NS, Brinkman CR, Nuwayhid B. Comparison of maternal and fetal cardiovascular functions in acute and chronic experiments in the sheep. Am J Obstet Gynecol 1974;120:411-25.

6. Hoffman JI, Payne BD, Heymann MA, Rudolph AM. The use of microspheres to measure blood flow. Prog Cardiovasc Dis $1977 ; 20: 55-79$. 
7. Heymann MA, Creasy RK, Rudolph AM. Quantitation of blood flow patterns in the foetal lamb in utero. In: Comline RS, Gross KW, Daves GW, Nathanielsz PW, eds. Foetal and Neonatal Physiology, Proceedings of the Sir Joseph Barcoft Centenary Symposium, Cambridge: Cambridge University Press, 1973;129-35.

8. Itskovitz J, Goetzman BW, Roman C, Rudolph AM. Effects of fetal-maternal exchange transfusion on fetal oxygenation and blood flow distribution. Am Physiol Soc 1984;247:H655-60.

9. Goetzman BW, Itskovitz J, Rudolph AM. Fetal adaptations to spontaneous hypoxemia and responses to maternal oxygen breathing. Biol Neonate 1984;46:276-84.

10. Cohn HE, Sacks EJ, Heymann MA, Rudolph AM. Cardiovascular responses to hypoxemia and acidemia in fetal lambs. Am J Obstet Gynecol 1974;120:817-24.

11. Rudolph AM, Heymann MA. Circulatory changes during growth in the fetal lamb. Circ Res 1970;26:289-99.

12. Iwammoto HS, Rudolph AM. Role of renin-angiotension system in response to hemorrhage in fetal sheep. Am Physiol Soc 1981;240:H848-54.

13. Iwammoto HS, Rudolph AM. Effects of angiotension II on the blood flow and its distribution in fetal lambs. Circ Res 1981;48:183-9.

14. Iwammoto HS, Rudolph AM, Heymann MA. Hemodynamic responses of the sheep fetus to vasopressin infusion. Circ Res 1979;44:430-6.

15. Turley $K$, Vlahakes GJ, Harrison MR, et al. Intrauterine cardiothoracic surgery: the fetal lamb model. Ann Thorac Surg 1982;34:422-6.

16. Rankin JHG. Role of prostaglandins in the maintenance of the placental circulation. In: Coceani F, Olley PM, eds. Advances in prostaglandin and thromboxane research. Vol 4. New York: Raven Press, 1978:261-9.

17. Tripp ME, Heymann MA, Rudolph AM, Hemodynamic effects of prostaglandin $E_{1}$ on lambs in utero. In: Coceani F, Olley PM, eds. Advances in prostaglandin and thromboxane research. Vol 4. New York: Raven Press, 1978:2219.

18. Challsi JRG, Dilley SR, Robinson JS, Thorburn GD. Prostaglandins in the circulation of the fetal lamb. Prostaglandins 1975;11:1041-52.

19. Berman W, Goodlin RC, Heymann MA, Rudolph AM. Effects of pharmacologic agents on umbilical blood flow in fetal lambs in utero. Biol Neonate 1978;33:225-35.

20. Novy MJ, Piasecki G, Jackson BT. Effect of prostaglandins $E_{2}$ and $F_{2 \alpha}$ on umbiblical blood flow and fetal hemodynamics. Prostaglandins 1974;5:543-55.

21. McLaughlin MK, Brennan SC, Chez RA. Effects of indomethacin on sheep uteroplacental circulations and sensitivity to angiotension II. Am J Obstet Gynecol 1978; 132:430-5.

22. Parisi VM, Walsh SW. Arachidonic acid metabolites and the regulation of placental and other vascular tone during pregnancy. Semin Perinatol 1986;10:288-98.

23. Tuvemo $T$. Role of prostaglandins, prostacyclin, and thromboxanes in the control of the umbilical-placental circulation. Semin Perinatol 1980;4:91-5.

24. Rudolph AM, Heymann MA. Hemodynamic changes induced by blockers of prostaglandin synthesis in the fetal lamb in utero. In: Coceani F, Olley PM, eds. Advances in prostaglandin and thromboxane research. Vol 4. New York: Raven Press, 1978:231-7.

25. Challis JRG, Hart I, Louis TM, et al. Prostaglandins in the sheep fetus: implications for fetal function. In: Coceani $F$, Olley PM, eds. Advances in prostaglandin and thromboxane research. Vol 4. New York: Raven Press, 1978:1 15-32.

26. Greeley WJ, Bushman GA, Kong DL, Oldham HN, Peterson MB. Effects of cardiopulmonary bypass on eicosanoid metabolism during pediatric cardiovascular surgery. J THORAC CARdIOVASC SURG 1980;79:91-6.

27. Addonizio VP, Smith JB, Strauss JF, Colman RW, Edmunds LH. Thromboxane synthesis and platelet secretion during cardiopulmonary bypass with bubble oxygenator. J THORAC CARDIOVASC SuRG 1980;79:91-6.

28. Faymonville ME, Deby-Dupont G, Larbuisson R, et al. Prostaglandin $E_{2}$, prostacyclin, and thromboxane changes during nonpulsatile cardiopulmonary bypass in humans. $\mathbf{J}$ ThORAC Cardiovasc SuRg 1986;91:959-66.

29. Watkins WD, Peterson MB, Kong DL, et al. Thromboxane and prostacyclin changes during cardiopulmonary bypass with and without pulsatile flow. J THORAC CARDIOVASC SURG 1982;84:250-6.

30. Ylikorkala O, Saarela E, Viinikka L. Increased prostacyclin and thromboxane production in man during cardiopulmonary bypass. J THORAC CARDIOVASC SURG 1981; $82: 245-7$

\section{Discussion}

Dr. Pierantionio Russo (Philadelphia, Pa.). We, at Temple University, have been interested in this type of work for some time. We too have been searching for factors affecting placental and umbilical blood flow during and after cardiopulmonary bypass in the fetal lamb model. However, our circuit differs slightly from the one described by the authors, because we have used a membrane oxygenator to control arterial blood gases and acid-base homeostasis. We think that this is particularly important if one wants to simulate clinical cardiopulmonary bypass by cooling and rewarming the fetus. We concur with the authors that during cardiopulmonary bypass placental blood flow decreases because of increased resistance. In the instrumented fetal lamb with transonic flow probes positioned around the isolated umbilical arteries, we have found that during simulated cardiopulmonary bypass, umbilical blood flow can be manipulated by changing the temperature of the prime and by use of $\alpha$-adrenergic blockers. In particular, at constant pressure and flow in the descending aorta, umbilical blood flow is minimal at $20^{\circ} \mathrm{C}$, but it returns to baseline during rewarming of the fetus to $39^{\circ} \mathrm{C}$.

I have two questions for the authors. First, did you return any of these fetuses back into the uterus after successful use of indomethacin and steroids? We have been recently approaching the problem of fetal survival after cardiopulmonary bypass 
by delivering the fetuses and then maintaining them on liquid ventilation. Second, do you think that indomethacin, although preserving placental blood flow, may actually interfere with fetal survival by inducing premature closure of the ductus arteriosus?

Dr. Sabik. Thank you, Dr. Russo, for your comments. We did not place an oxygenator in our bypass circuit because it would not have allowed us to evaluate how well the fetal placenta was functioning during fetal bypass by measuring fetal arterial blood gases. If we had added an oxygenator to the circuit, while the fetuses were on bypass the fetal arterial blood gas measurements would have represented how well the oxygenator was functioning, and not the placenta.

Regarding temperature, we have performed isolated placental studies with varying perfusion temperatures, and we have found higher placental vascular resistances with hypothermic placental bypass than with normothermic placental bypass. However, we determined that this increased placental vascular resistance during hypothermic bypass was due solely to the increased viscosity of blood at the lower temperatures.
To answer your question about long-term studies, if we use indomethacin alone during fetal cardiac bypass, the fetuses will survive for 6 hours after being weaned from bypass. They die of a delayed placental dysfunction that is due to increased placental vascular resistance. It appears that indomethacin is able to block this response of increased placental vascular resistance for only a short period of time. However, if during fetal bypass we administer indomethacin with a fetal anesthetic that is able to prevent what we term "the fetal stress response to surgery," these fetuses survive to complete gestation. These studies are currently under investigation.

In an earlier article, we addressed the question of the effect of indomethacin on the ductus. Using a pulmonary arterial line in the main pulmonary artery and a femoral arterial line, we did not observe any pressure gradients across the ductus after administration of indomethacin.

\section{Bound volumes available to subscribers}

Bound volumes of THE JOURnAl of THORACIC AND CARdiovascular SuRgery are available to subscribers (only) for the 1994 issues from the Publisher, at a cost of $\$ 82.50$ for domestic, $\$ 106.28$ for Canadian, and $\$ 100.50$ for international subscribers for Vol. 107 (January-June) and Vol. 108 (July-December). Shipping charges are included. Each bound volume contains a subject and author index and all advertising is removed. Copies are shipped within 60 days after publication of the last issue of the volume. The binding is durable buckram with the JOURNAL name, volume number, and year stamped in gold on the spine. Payment must accompany all orders. Contact Mosby-Year Book, Inc., Subscription Services, 11830 Westline Industrial Drive, St. Louis, Missouri 63146-3318, USA; phone 1 (800) 4534351 or (314) 453-4351.

Subscriptions must be in force to qualify. Bound volumes are not available in place of a regular JourNaL subscription. 